\title{
Prehypertension among young adult females in Dammam, Saudi Arabia
}

\author{
M.R. Koura, ${ }^{1}$ B.K. Al-Dabal, ${ }^{1}$ P. Rasheed, ${ }^{1}$ L.S. Al-Sowielem ${ }^{7}$ and S.M. Makki ${ }^{1}$
}

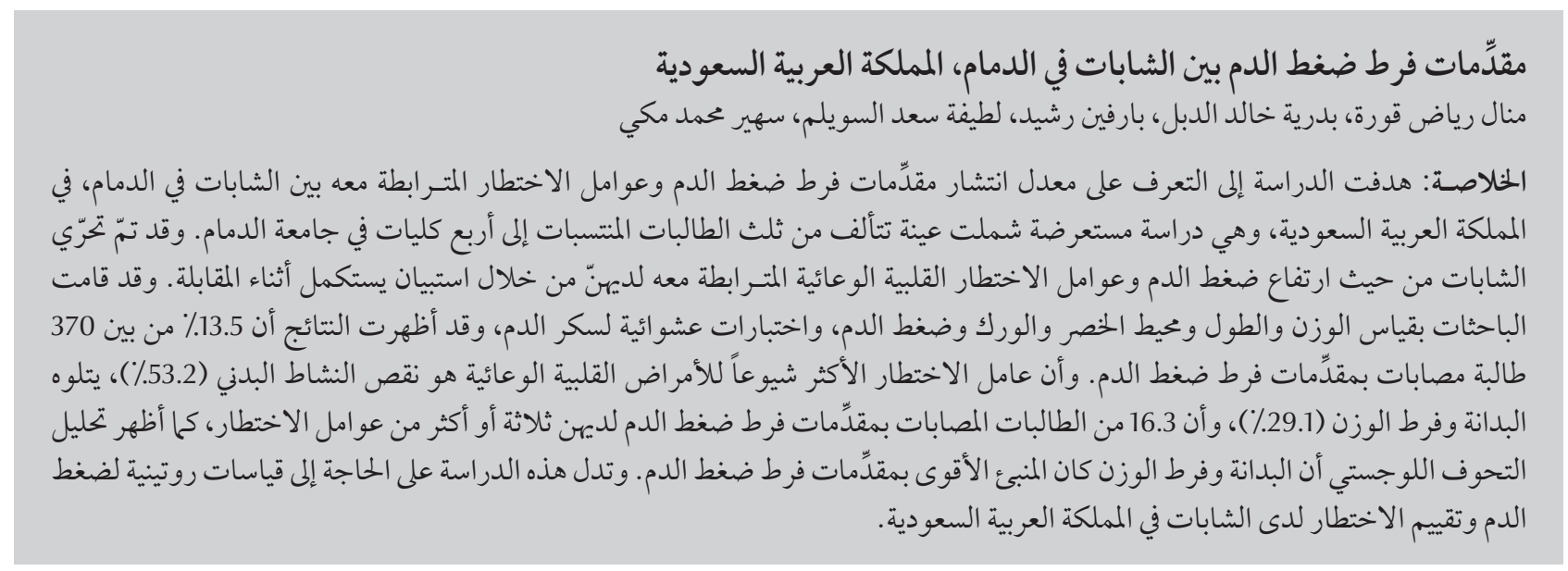

ABSTRACT The aim of present study was to determine the prevalence of prehypertension and associated risk factors among young adult females in Dammam, Saudi Arabia. A cross-sectional study was conducted on a sample of about one-third of female students enrolled in 4 colleges of the University of Dammam. They were screened for high blood pressure and associated cardiovascular risk factors by an interview questionnaire. Weight and height, waist and hip and blood pressure measurements and random blood glucose testing were done. The results revealed that $13.5 \%$ of the 370 students were prehypertensive. The most prevalent risk factor for cardiovascular diseases was physical inactivity (53.2\%), followed by overweight/obesity (29.1\%); 16.3\% of prehypertensive students had 3 or more risk factors. Logistic regression analysis revealed that overweight/ obesity was the strongest predictor of prehypertension. Our study indicates a need for routine blood pressure measurements and risk assessment in young adult females in Saudi Arabia.

\section{Préhypertension chez des jeunes femmes à Dammam (Arabie saoudite)}

RÉSUMÉ L'objectif de la présente étude était de déterminer la prévalence de la préhypertension et les facteurs de risque associés chez des jeunes femmes à Dammam (Arabie saoudite). Une étude transversale a été menée sur un échantillon d'environ un tiers des étudiantes inscrites dans quatre facultés de l'Université de Dammam. Les étudiantes ont bénéficié d'un dépistage de l'hypertension artérielle. Les facteurs de risque cardio-vasculaire associés ont été recueillis par questionnaire lors d'un entretien. La taille et le poids, le tour de taille et des hanches ont été mesurés, ainsi que la tension artérielle. En outre, une analyse de la glycémie a été effectuée de manière aléatoire. Les résultats ont révélé que 13,5\% des 370 étudiantes souffraient de préhypertension. Les facteurs de risque les plus prévalents pour les maladies cardio-vasculaires étaient la sédentarité (53,2 \%), suivie par la surcharge pondérale/l'obésité $(29,1 \%) ; 16,3 \%$ des étudiantes préhypertendues présentaient trois facteurs de risque ou plus. L'analyse de régression logistique a mis en évidence le fait que la surcharge pondérale/l'obésité était le facteur prédictif le plus important de la préhypertension. Notre étude souligne la nécessité d'une surveillance systématique de la tension artérielle et d'une évaluation des risques chez les jeunes femmes en Arabie saoudite. 


\section{Introduction}

Chronic diseases such as cardiovascular diseases (CVD) are rising dramatically in the Eastern Mediterranean Region. About $45 \%$ of the region's disease burden is due to noncommunicable diseases and it is expected that this burden will rise to $60 \%$ by the year 2020 . Primary prevention, with a focus on reducing avoidable risk factors, is the most cost-effective approach to containing this emerging epidemic [1]. One of these risk factors is hypertension, which is associated with an increased risk of morbidity and mortality from CVD and is one of the main preventable causes of death.Prospective observational studies have suggested that the risk of CVD death begins at systolic/diastolic blood pressure (BP) 115/75 $\mathrm{mm} \mathrm{Hg}$ and doubles for each increment of $20 / 10$ $\mathrm{mm} \mathrm{Hg}$ in a nearly linear fashion. Also, arterial stiffness and other abnormal effects begin long before the $140 / 90 \mathrm{~mm}$ $\mathrm{Hg}$ threshold at which clinicians began treating hypertension [2]. Accordingly, the Seventh Report of the Joint National Committee on Prevention, Detection, Evaluation and Treatment of High Blood Pressure (JNC7) introduced a new category, "prehypertension”, defined as systolic BP of 120-139 $\mathrm{mm} \mathrm{Hg}$ and/or a diastolic BP of 80-89 $\mathrm{mm} \mathrm{Hg}$, replacing former categories of "above optimal" and "high normal". The rationale for redefining this category was to emphasize the excess risk associated with $\mathrm{BP}$ in this range and to focus increased clinical and public health attention on prevention [3].

In Saudi Arabia a national study was conducted in 1998 to determine the prevalence of hypertension among the adult population. It revealed that its prevalence was higher among males (18.7\%) than females (14.0\%) and was highest in the Eastern province [4]. A more recent national study in 2007 reported a higher prevalence rate of hypertension among Saudi adults (28.6\% for males and $23.9 \%$ for females), indicating a rising trend in hypertension in Saudi Arabia [5]. Screening of young men for prehypertension in the Western region of Saudi Arabia in 2008 revealed that its prevalence was $17.3 \%[6]$, while among male university students in the Eastern region the prevalence was $32.7 \%$ [7]. Data on prehypertension in young adult females in the Eastern province, however, is lacking. Thus, the aim of the present study was to determine the prevalence of prehypertension and associated risk factors among young adult females in Dammam city, Eastern province, Saudi Arabia.

\section{Methods}

A cross-sectional study was conducted in the University of Dammam, after taking all the necessary academic and administrative approvals from the related authorities.

\section{Sample}

The target population consisted of 1300 female university students registered for the academic year 2005-06 in 4 colleges. The sample size was calculated using Epi Info, version 2.3.1. It was found that at expected frequency of prehypertension of $14 \%$ [4], at worst acceptable frequency of $\pm 3 \%$ and at a confidence level of $95 \%$, the minimum required sample size was 368 . Accordingly, 370 students were selected by multistage stratified random sampling with proportional allocation from the different colleges and academic levels. Within each level students were selected from the registration list by systematic random sampling, choosing every $3 \mathrm{rd}$ student until the proportionate sample was obtained. Pregnant students were excluded from the sample. The sample size represented about $28 \%$ of the target population.

\section{Data collection}

A modified Arabic version of the World Health Organization STEPwise approach to Surveillance (WHOSTEPS) instrument for collecting data on noncommunicable diseases risk factors was used, which was reviewed and approved by all members of the faculty of family and community medicine.

\section{Interviews}

Trained interviewers approached the selected students in their classrooms, informed them about the nature of the study, assured them about the confidentiality of collected data and requested their participation. Interviewers were specially trained to ask questions in a non-judgemental manner to avoid bias in responses.

The interview questionnaire collected data on sociodemographic details and risk factors for CVD (e.g. current daily tobacco smoking, moderate intensity physical activity for 30 minutes 3 times per week, hypercholesterolaemia, diabetes, hypertension and family history of hypertension), as well as dietary habits (e.g. frequency of consuming vegetables, fruits and fast food per week and type of fat used for cooking). The later was an open-ended question categorized into saturated or unsaturated fat by the researchers during data entry for statistical analysis.

\section{Physical measurements}

Physical measurements and blood samples were taken by a trained nurse during lunch time at the university clinic under the supervision of the research team and after taking informed consent from the participants. Weight and height were measured and body mass index (BMI) was calculated. It was classified into: normal weight (BMI 18.5-24.9 kg/ $\mathrm{m}^{2}$ ), overweight (BMI $25-29.9 \mathrm{~kg} / \mathrm{m}^{2}$ ) and obesity $\left(\mathrm{BMI} \geq 30 \mathrm{~kg} / \mathrm{m}^{2}\right)$. Waist to hip ratio was estimated and a value $\geq 0.8$ was considered as central obesity. Two BP measurements were taken while the student was seated and the average was recorded. BP was classified according to the JNC7 criteria as follows: normal < $120 \mathrm{~mm} \mathrm{Hg}$ systolic and < $80 \mathrm{~mm} \mathrm{Hg}$ diastolic; prehypertension: 120-139 
mm Hg systolic or $80-89 \mathrm{~mm} \mathrm{Hg} \mathrm{di-}$ astolic; hypertension: $\geq 140 \mathrm{~mm} \mathrm{Hg}$ systolic or $\geq 90 \mathrm{~mm} \mathrm{Hg}$ diastolic [3]. Students on anti-hypertensive medications were considered as hypertensive. Diabetes was considered if random capillary blood glucose was $>200 \mathrm{mg} /$ dL. Students on hypoglycaemic medications were considered as diabetic.

\section{Data analysis}

The collected data was analysed by SPSS, version 17. After verification of data, they were analysed and presented in descriptive tables. The chi-squared test was used for qualitative binomial analysis and Fisher exact test was used if the expected frequency was less than 5 in more than $20 \%$ of the cells. Logistic regression analysis of different sociodemographic characteristics and risk factors affecting prehypertension was conducted and a $P$-value of $<0.05$ was considered statistically significant.

\section{Results}

While all the 370 selected students agreed to respond to the questionnaire, 9 students declined to have their physical measurements and blood samples taken, giving a response rate of $97.6 \%$ for some of the data.

The mean age of the students was 19.9 (SD 1.4) years. The great majority were single (91.9\%) and the rest were married. More than half of the students' fathers were university graduates (53.5\%) and only $4.9 \%$ were illiterate, in comparison with $33.2 \%$ and $8.1 \%$ of the mothers respectively. Of the students 69.7\% came from high-income families and only $4.9 \%$ from low-income families.

It was found that $13.5 \%$ of these female university students had prehypertension (3.8\% had high normal BP 130-139 mm Hg systolic BP or 85-89 $\mathrm{mm} \mathrm{Hg}$ diastolic BP) and 2.7\% had hypertension. Only $40 \%$ of hypertensive students were aware of being hypertensive.

No significant associations between sociodemographic characteristics and high BP was detected. However, hypertension was more common among students from low-income families compared with high-income families $(11.8 \%$ versus $1.6 \%)(P=0.059)$ (Table 1).

The most prevalent risk factor for high BP among these female university students was physical inactivity (53.2\%), followed by overweight and obesity (20.6\% and $8.5 \%$ respectively; $29.1 \%$ overall), family history of hypertension (17.6\%) and central obesity (6.6\%) (Table 2).

Table 2 also shows a strong association between high BP and overweight/obesity, diabetes and

\begin{tabular}{|c|c|c|c|c|c|}
\hline \multirow[t]{3}{*}{ Sociodemographic characteristic } & \multirow{3}{*}{$\begin{array}{l}\text { Total } \\
\text { No. }\end{array}$} & \multicolumn{3}{|c|}{ Blood pressure group } & \multirow[t]{3}{*}{$P$-value } \\
\hline & & Normal & Prehypertension & Hypertension & \\
\hline & & $\%$ & $\%$ & $\%$ & \\
\hline \multicolumn{6}{|l|}{ Age (years) } \\
\hline$<20$ & 165 & 81.0 & 15.8 & 3.2 & \multirow[t]{2}{*}{0.487} \\
\hline$\geq 20$ & 205 & 85.7 & 11.8 & 2.5 & \\
\hline \multicolumn{6}{|l|}{ Marital status } \\
\hline Single & 340 & 83.5 & 14.1 & 2.4 & \multirow[t]{2}{*}{0.183} \\
\hline Married & 30 & 85.7 & 7.1 & 7.1 & \\
\hline \multicolumn{6}{|l|}{ Father's education } \\
\hline Illiterate/read \& write & 18 & 83.3 & 11.1 & 5.6 & \multirow[t]{4}{*}{0.936} \\
\hline Primary/preparatory & 51 & 82.4 & 15.7 & 2.0 & \\
\hline Secondary/diploma & 103 & 85.0 & 12.0 & 3.0 & \\
\hline University/postgraduate & 198 & 83.2 & 14.1 & 2.6 & \\
\hline \multicolumn{6}{|l|}{ Mother's education } \\
\hline Illiterate/read \& write & 30 & 86.7 & 13.3 & 0.0 & \multirow[t]{4}{*}{0.791} \\
\hline Primary/preparatory & 110 & 81.1 & 14.2 & 4.7 & \\
\hline Secondary/diploma & 107 & 86.3 & 12.7 & 1.0 & \\
\hline University/postgraduate & 123 & 82.9 & 13.8 & 3.3 & \\
\hline \multicolumn{6}{|l|}{ Income } \\
\hline Low & 18 & 82.4 & 5.9 & 11.8 & \multirow[t]{4}{*}{0.059} \\
\hline Middle & 94 & 86.2 & 9.6 & 4.3 & \\
\hline High & 258 & 82.8 & 15.6 & 1.6 & \\
\hline Total & 370 & 83.6 & 13.5 & 2.7 & \\
\hline
\end{tabular}




\begin{tabular}{|c|c|c|c|c|c|}
\hline \multirow[t]{3}{*}{ Risk factor } & \multirow{3}{*}{$\begin{array}{l}\text { Total } \\
\text { No. }\end{array}$} & \multicolumn{3}{|c|}{ Blood pressure group } & \multirow[t]{3}{*}{$P$-value } \\
\hline & & Normal & Prehypertension & Hypertension & \\
\hline & & $\%$ & $\%$ & $\%$ & \\
\hline Physical inactivity & & & & & 0.54 \\
\hline Yes & 197 & 83.3 & 13.0 & 3.6 & \\
\hline No & 173 & 84.0 & 14.2 & 1.8 & \\
\hline Overweight/obesity ${ }^{a}$ & & & & & 0.001 \\
\hline Yes & 105 & 71.7 & 24.5 & 3.8 & \\
\hline No & 256 & 88.6 & 9.0 & 2.4 & \\
\hline Family history of hypertension & & & & & 0.42 \\
\hline Yes & 65 & 82.0 & 14.8 & 3.3 & \\
\hline No & 305 & 87.2 & 11.1 & 1.7 & \\
\hline Central obesity ${ }^{a}$ & & & & & 0.50 \\
\hline Yes & 24 & 78.3 & 17.4 & 4.3 & \\
\hline No & 337 & 83.6 & 13.7 & 2.7 & \\
\hline Hypercholesterolaemia & & & & & 0.001 \\
\hline Yes & 12 & 58.3 & 8.3 & 33.3 & \\
\hline No & 358 & 84.1 & 14.0 & 1.8 & \\
\hline Smoking & & & & & 1.00 \\
\hline Yes & 5 & 100.0 & 0.0 & 0.0 & \\
\hline No & 365 & 83.4 & 13.8 & 2.8 & \\
\hline Diabetes $^{a}$ & & & & & 0.001 \\
\hline Yes & 4 & 25.0 & 0.0 & 75.0 & \\
\hline No & 357 & 84.3 & 13.7 & 2.0 & \\
\hline
\end{tabular}

${ }^{a} 9$ students declined to participate.

hypercholesterolaemia. One-quarter of overweight/obese female university students (24.5\%) had prehypertension and $3.8 \%$ had hypertension, compared with only $9.0 \%$ and $2.4 \%$ of normal weight students respectively. Three quarters $(75.0 \%)$ of diabetic students had hypertension, compared with only $2.0 \%$ of non-diabetic students. Also, about one-third of hypercholesterolaemic students (33.3\%) had hypertension, compared with only $1.8 \%$ of students with cholesterol in the normal range. These differences were highly statistically significant $(P<0.001)$. No significant associations between high $\mathrm{BP}$ and physical inactivity, family history of hypertension and central obesity were recognized. All the students who smoked $(n=5)$ were normotensive.

Table 3 shows that $71.4 \%$ of female prehypertensive students had 1 or more CVD risk factors; $32.7 \%$ had
1 risk factor, $22.4 \%$ had 2 risk factors and $16.3 \%$ had 3 or more risk factors. A positive correlation between number of risk factors and BP was also recognized, as $30.0 \%$ of hypertensive students and $16.3 \%$ of prehypertensive students had 3 or more risk factors compared with only $4.6 \%$ of normotensive students $\left(\chi^{2}\right.$ $=11.79$, Fisher exact $P=0.047$ ).

Table 4 reveals that $31.9 \%$ of the families of female university students used saturated fat for cooking, as $16.5 \%$ used saturated fat only and $15.4 \%$ used a combination of saturated and unsaturated fat. It also showed that some of the female students did not eat vegetables or fruits at all (3.0\% and 9.5\% respectively) and only $45.1 \%$ and $28.6 \%$ respectively ate them daily. Regarding "fast food" consumption, it was found that $20.9 \%$ ate this at least 4 times per week. No significant differences were found between normotensive and prehypertensive or hypertensive students regarding food habits.

Sociodemographic characteristics (age, marital status, mother's education and family income) as well as risk factors (overweight/obesity, physical inactivity, hypercholesterolaemia and family history of hypertension) were included in the logistic regression analysis model. It revealed that overweight/obesity was a significant predictor of prehypertension among female university students, with an odds ratio of 3.34 (95\% CI: 1.77-6.30) (Table 5).

\section{Discussion}

Several recent studies have reported an increased risk of CVD among prehypertensive people, especially among those with high normal BP. The Framingham Heart Study indicated that men and 


\begin{tabular}{|c|c|c|c|c|}
\hline $\begin{array}{l}\text { Table } 3 \text { Num } \\
\text { students by }\end{array}$ & $\begin{array}{l}\text { f cardiovas } \\
\text { pressure }\end{array}$ & $\begin{array}{l}\text { dar disease risk fac } \\
\text { oup }\end{array}$ & tors among fem & university \\
\hline No. of risk & & lood pressure grou & & Total \\
\hline factors & $\begin{array}{l}\text { Normal } \\
(n=310)\end{array}$ & $\begin{array}{l}\text { Prehypertension } \\
\qquad(\boldsymbol{n}=\mathbf{5 0})\end{array}$ & $\begin{array}{l}\text { Hypertension } \\
\qquad(n=10)\end{array}$ & $(n=370)$ \\
\hline & $\%$ & $\%$ & $\%$ & $\%$ \\
\hline 0 & 27.5 & 28.6 & 0.0 & 26.9 \\
\hline 1 & 45.4 & 32.7 & 30.0 & 43.2 \\
\hline 2 & 22.5 & 22.4 & 40.0 & 23.0 \\
\hline $3+$ & 4.6 & 16.3 & 30.0 & 6.9 \\
\hline
\end{tabular}

$\chi^{2}=11.79$, Fisher exact $P=0.047$

women with high normal BP had a more than 2 -fold increase in relative risk for CVD compared with those who had optimal BP [8-11]. Prehypertension is associated with subclinical atherosclerosis, including increased coronary atherosclerosis and increased arterial intima-media thickness. In addition, prehypertension is associated with elevated C-reactive protein, tumour necrosis factor $\alpha$, homocysteine, oxidized low-density lipoprotein cholesterol and other inflammatory markers $[9,12,13]$.
The present study revealed that $13.5 \%$ of female university students in Dammam in the Eastern province of Saudi Arabia had prehypertension. A similar study conducted in the same region on male university students recorded a higher prevalence of prehypertension (32.7\%) [7]. In comparison $35.8 \%$ of Israeli females and $56.8 \%$ of males aged 16.5-19 years were considered prehypertensive [14]. Many recent studies conducted in different countries reported similar sex differences.
Prehypertension was recognized to be more common among males than females, regardless of age [15-18]. Also, national studies conducted in Saudi Arabia revealed that hypertension was more common among males than females $[4,5]$.

The numerous risk factors for CVD other than hypertension are usually categorized as modifiable (e.g. dyslipidaemia, smoking, diabetes, abdominal obesity, excess alcohol intake and sedentary lifestyle) and non-modifiable (e.g. increasing age, male sex and family history of premature CVD). The rate of these risk factors have been found to be higher in prehypertensive than normotensive subjects, at rates between those with normotension and hypertension $[16,19,20]$. The present study revealed that the most prevalent risk factor among female university students was physical inactivity, followed by overweight/obesity, family history of hypertension and central obesity. By comparing the prevalence

\begin{tabular}{|c|c|c|c|c|c|}
\hline \multirow[t]{3}{*}{ Dietary habit } & \multirow{3}{*}{$\begin{array}{l}\text { Total } \\
\text { No. }\end{array}$} & \multicolumn{3}{|c|}{ Blood pressure group } & \multirow[t]{3}{*}{$P$-value } \\
\hline & & Normal & Prehypertension & Hypertension & \\
\hline & & $\%$ & $\%$ & $\%$ & \\
\hline \multicolumn{6}{|l|}{ Cooking fat } \\
\hline Saturated & 61 & 88.7 & 11.3 & 0.0 & \multirow[t]{3}{*}{0.162} \\
\hline Unsaturated & 252 & 81.6 & 15.8 & 2.6 & \\
\hline Combined & 57 & 83.0 & 9.4 & 7.5 & \\
\hline \multicolumn{6}{|c|}{$\begin{array}{l}\text { Frequency of vegetable } \\
\text { consumption (times/week) }\end{array}$} \\
\hline 0 & 11 & 81.8 & 18.2 & 0.0 & \multirow[t]{3}{*}{0.764} \\
\hline $1-6$ & 192 & 83.2 & 13.0 & 3.8 & \\
\hline $7+$ & 167 & 84.6 & 13.6 & 1.9 & \\
\hline \multicolumn{6}{|c|}{$\begin{array}{l}\text { Frequency of fruit consumption } \\
\text { (times/week) }\end{array}$} \\
\hline 0 & 35 & 82.9 & 11.4 & 5.7 & \multirow[t]{3}{*}{0.729} \\
\hline $1-6$ & 229 & 83.2 & 14.5 & 2.3 & \\
\hline $7+$ & 106 & 84.6 & 12.5 & 2.9 & \\
\hline \multicolumn{6}{|c|}{$\begin{array}{l}\text { Frequency of fast food consumption } \\
\text { (times/week) }\end{array}$} \\
\hline 0 & 21 & 90.0 & 10.0 & 0.0 & \multirow[t]{3}{*}{0.994} \\
\hline $1-3$ & 272 & 82.8 & 14.2 & 3.1 & \\
\hline $4+$ & 77 & 83.8 & 13.5 & 2.7 & \\
\hline
\end{tabular}




\begin{tabular}{|c|c|c|}
\hline \multicolumn{3}{|c|}{$\begin{array}{l}\text { Table } 5 \text { Logistic regression analysis of sociodemographic characteristics and risk } \\
\text { factors for prehypertension among female university students }\end{array}$} \\
\hline \multirow[t]{2}{*}{ Variable } & \multicolumn{2}{|c|}{ Risk of prehypertension } \\
\hline & OR $(95 \% \mathrm{Cl})$ & $P$-value \\
\hline Age & $0.77(0.41-1.45)$ & 0.419 \\
\hline Marital status & $0.70(0.15-3.28)$ & 0.645 \\
\hline Mother's education & $0.86(0.61-1.22)$ & 0.395 \\
\hline Family income & $1.69(0.82-3.47)$ & 0.153 \\
\hline Physical inactivity & $0.77(0.41-1.45)$ & 0.419 \\
\hline Overweight/obesity & $3.34(1.77-6.30)$ & 0.001 \\
\hline Family history of hypertension & $0.80(0.40-1.62)$ & 0.541 \\
\hline Hypercholesterolaemia & $1.83(0.21-16.2)$ & 0.589 \\
\hline
\end{tabular}

$O R=$ odds ratio; $C l=$ confidence interval.

of overweight/obesity (29.1\%) with similar studies, it was found to be relatively high, as $14 \%$ of Israeli and 15\% of American adolescent girls were classed as overweight/obese [14,21].

Regression analysis revealed that overweight/obesity was a significant predictor of prehypertension in our study. Similar findings were reported by several other studies $[6,14,17,18,22,23]$. The association between BP and weight is strong and linear, even in the normal range of $\mathrm{BP}$ and $\mathrm{BMI}[24]$. Al-Hazza, who reviewed 3 national cross-sectional studies conducted in Saudi Arabia, reported an increasing prevalence of BMI over time in the adolescent population [25]. Consequently, a rising trend in prevalence of prehypertension is expected among young adults in the coming decades.

In contrast with the results on BMI, central obesity was not associated with high BP in our study. Similar findings were reported by a study conducted on a Japanese population, where the risks for CVD incidence were similar among participants who had the same number of risk factors, with and without abdominal obesity [26].

Certain factors have been shown to be protective against the development of CVD, namely daily consumption of fruits and vegetables and regular physical activity [27]. According to the present study fruits and vegetables were consumed daily by only $28.6 \%$ and $45.1 \%$ of female university students respectively. However, no relationship was found between high blood pressure and food habits.

Like hypertension, prehypertension tends to cluster with other CVD risk factors. The proportion of prehypertensive individuals with 1 or more risk factor is about $85 \%$ [28]. The increased risk of CVD resulting from multiple risk factors is frequently greater than simply additive, indicating a synergistic effect [29]. According to the present study, $71.4 \%$ of female prehypertensive university students had at least 1 other risk factor for CVD and $16.3 \%$ had 3 or more risk factors.

As with hypertension, prehypertension tends to increase in severity over time. Progression of prehypertension to clinical hypertension depends on the level of BP and age. Yearly measurement of $\mathrm{BP}$ in patients with prehypertension is recommended by the JNC-7 to detect and treat hypertension as early as possible [3]. The 2003 European Societies of Hypertension and Cardiology guidelines emphasize the importance of a complete risk assessment for prehypertensive people. The search for other CVD risk factors, e.g. diabetes, obesity or dyslipidaemia, and the presence of target organ damage, e.g. left ventricular hypertrophy, microalbuminuria or increased carotid intima-media thickness, should be encouraged [30]. Japanese guidelines for the management of hypertension published in 2009 consider patients to be in a high-risk group (and requiring antihypertensive therapy) if they have diabetes, chronic kidney disease, 3 or more risk factors, target organ damage or CVD, even if they have only high normal BP [31]. According to JNC-7 the following major lifestyle modifications are recommended for management of prehypertension: weight reduction; the Dietary Approaches to Stop Hypertension (DASH) eating plan, which is rich in potassium and calcium and reduced in total and saturated fat; reduced sodium intake; regular aerobic physical exercise; and moderation of alcohol intake. However, the JNC-7 report recommends drug treatment "if a trial of lifestyle modification fails to reduce BP to $130 / 80 \mathrm{~mm} \mathrm{Hg}$ or less" in patients with either diabetes mellitus or chronic kidney disease [3]. Our findings, mainly that overweight/obesity was a major determinant of prehypertension, that physical inactivity was common and that daily consumption of fruits and vegetables was uncommon, indicate that lifestyle modification would probably be the most effective strategy for management of prehypertension among this group of young adult females.

Our study had some limitations, such as random blood glucose testing and assessment of hypercholesterolaemia by history-taking, which may have resulted in underestimation of these risk factors. Therefore it was not always possible to compare our findings with similar studies.

In conclusion, our study demonstrates that prehypertension was prevalent in female university students in Dammam and was associated with multiple CVD risk factors. These results underline the need for routine BP measurements in young adults to identify subjects with prehypertension, who should be the target for annual measurement of BP, assessment for other CVD risk factors and lifestyle modifications. 
1. Report on the follow-up consultation on the Eastern Mediterranean Approach to Noncommunicable Diseases Network. Cairo, World Health Organization Regional Office for the Eastern Mediterranean, 2003 (WHO-EM/NCD/039/E/L/100).

2. Lewington $\mathrm{S}$ et al. Prospective Studies Collaboration. Agespecific relevance of usual blood pressure to vascular mortality: a meta-analysis of individual data for one million adults in 61 prospective studies. Lancet, 2002, 360:1903-1913

3. Chobanian AV et al. Seventh report of the Joint National Committee on prevention, detection, evaluation and treatment of high blood pressure. Hypertension, 2003, 42:1206-1252.

4. El-Hazmi MF, Warsy AS, AI-Swailem AR. Prevalence of hypertension in adult Saudi population. Saudi Medical Journal, 1998 19:117-122.

5. Al-Nozha MM et al. Hypertension in Saudi Arabia. Saudi Medical Journal, 2007, 28:77-84

6. Al-Asmary SM et al. Community-based screening for prehypertension among military active duty personnel. Saudi Medical Journal, 2008, 29:1779-1784.

7. Sabra AA et al. Coronary heart disease risk factors: prevalence and behavior among male university students in Dammam City, Saudi Arabia. Journal of the Egyptian Public Health Association, 2007, 82:21-42.

8. Liszka HA et al. Prehypertension and cardiovascular morbidity. Annals of Family Medicine, 2005, 3:294-299.

9. Washio $\mathrm{M}$ et al. Role of prehypertension in the development of coronary atherosclerosis in Japan. Journal of Epidemiology, 2004, 14:57-62.

10. Kokubo $\mathrm{Y}$ et al. Impact of high-normal blood pressure on the risk of cardiovascular disease in a Japanese urban cohort: the Suita study. Hypertension, 2008, 52:652-659.

11. Vasan RS et al. Impact of high-normal blood pressure on the risk of cardiovascular disease. New England Journal of Medicine, 2001, 345:1291-1297.

12. Toikka JO et al. Increased arterial intima-media thickness and in vivo LDL oxidation in young men with borderline hypertension. Hypertension, 2000, 36:929-933.

13. Chrysohoou $\mathrm{C}$ et al. Association between prehypertension status and inflammatory markers related to atherosclerotic disease: The ATTICA Study. American Journal of Hypertension, 2004, 17:568-573.

14. Israeli E et al. Prehypertension and obesity in adolescents: a population study. American Journal of Hypertension, 2006, 19:708-712.

15. Ferguson TS et al. Prevalence of prehypertension and its relationship to risk factors for cardiovascular disease in Jamaica: analysis from a cross-sectional survey. BMC Cardiovascular Disorders, 2008, 8:20.

16. Tsai PS et al. Prevalence and determinants of prehypertension status in the Taiwanese general population. Journal of Hypertension, 2005, 23:1355-1360.
17. Kawamoto R et al. High prevalence of prehypertension is associated with the increased body mass index in communitydwelling Japanese. Tohoku Journal of Experimental Medicine, 2008, 216:353-361.

18. Yu D et al. Prevalence and risk factors of prehypertension among Chinese adults. Journal of Cardiovascular Pharmacology, 2008, 52:363-368.

19. Bhatt DL et al. REACH Registry Investigators. International prevalence, recognition, and treatment of cardiovascular risk factors in outpatients with atherothrombosis. Journal of the American Medical Association, 2006, 295:180-189.

20. Zhang Y et al. Prehypertension, diabetes, and cardiovascular disease risk in a population-based sample: the Strong Heart Study. Hypertension, 2006, 47:410-414.

21. Bibbins-Domingo $\mathrm{K}$ et al. Adolescent overweight and future adult coronary heart disease. New England Journal of Medicine, 2007, 357:2371-2379.

22. Grotto I et al. Prevalence of prehypertension and associated cardiovascular risk profiles among young Israeli adults. Hypertension, 2006, 48:254-259.

23. Pang $\mathbf{W}$ et al. Body mass index and the prevalence of prehypertension and hypertension in a Chinese rural population. Internal Medicine, 2008, 47:893-897.

24. Sharabi $Y$ et al. Susceptibility of the influence of weight on blood pressure in men versus women: lessons from a largescale study of young adults. American Journal of Hypertension, 2004, 17:404-408.

25. Al-Hazzaa HM. Rising trends in BMI of Saudi adolescents: evidence from three national cross sectional studies. Asia Pacific Journal of Clinical Nutrition, 2007, 16:462-466.

26. Matsuzawa Y. Metabolic syndrome-definition and diagnostic criteria in Japan. Journal of Atherosclerosis and Thrombosis, 2005, 12:301.

27. McManus B. INTERHEART: nine factors that could save your life. Healthcare Quarterly, 2005, 8:28.

28. Mainous AG 3rd et al. Prehypertension and mortality in a nationally representative cohort. American Journal of Cardiology, 2004, 94:1496-1500

29. Thomas F et al. Combined effects of systolic blood pressure and serum cholesterol on cardiovascular mortality in young (<55 years) men and women. European Heart Journal, 2002, 23:528-535.

30. European Society of Hypertension-European Society of Cardiology Guidelines Committee. 2003 European Society of Hypertension-European Society of Cardiology guidelines for the management of arterial hypertension. Journal of Hypertension, 2003, 21:1011-1053.

31. Ogihara T et al. Japanese Society of Hypertension Committee. The Japanese Society of Hypertension Guidelines for the Management of Hypertension (JSH 2009). Hypertension Research, 2009, 32:3-107. 